University of Nebraska - Lincoln

DigitalCommons@University of Nebraska - Lincoln

1995

\title{
Using Known Populations of Pronghorn to Evaluate Sampling Plans and Estimators
}

Kathy M. Kraft

USGS Northern Prairie Wildlife Research Center

Douglas H. Johnson

USGS Northern Prairie Wildlife Research Center, Douglas_H_Johnson@usgs.gov

Jack M. Samuelson

North Dakota Game and Fish Department

Stephen H. Allen

North Dakota Game and Fish Department

Follow this and additional works at: https://digitalcommons.unl.edu/usgsnpwrc

Part of the Other International and Area Studies Commons

Kraft, Kathy M.; Johnson, Douglas H.; Samuelson, Jack M.; and Allen, Stephen H., "Using Known Populations of Pronghorn to Evaluate Sampling Plans and Estimators" (1995). USGS Northern Prairie Wildlife Research Center. 220.

https://digitalcommons.unl.edu/usgsnpwrc/220

This Article is brought to you for free and open access by the US Geological Survey at DigitalCommons@University of Nebraska - Lincoln. It has been accepted for inclusion in USGS Northern Prairie Wildlife Research Center by an authorized administrator of DigitalCommons@University of Nebraska - Lincoln. 


\title{
USING KNOWN POPULATIONS OF PRONGHORN TO EVALUATE SAMPLING PLANS AND ESTIMATORS
}

KATHY M. KRAFT,' National Biological Survey, Northern Prairie Science Center, Jamestown, ND 58401, USA DOUGLAS H. JOHNSON, National Biological Survey, Northern Prairie Science Center, Jamestown, ND 58401, USA JACK M. SAMUELSON, North Dakota Game and Fish Department, Mott, ND 58646, USA

STEPHEN H. ALLEN, North Dakota Game and Fish Department, Bismarck, ND 58501, USA

\begin{abstract}
Although sampling plans and estimators of abundance have good theoretical properties, their performance in real situations is rarely assessed because true population sizes are unknown. We evaluated widely used sampling plans and estimators of population size on 3 known clustered distributions of pronghorn (Antilocapra americana). Our criteria were accuracy of the estimate, coverage of $95 \%$ confidence intervals, and cost. Sampling plans were combinations of sampling intensities (16,33, and 50\%), sample selection (simple random sampling without replacement, systematic sampling, and probability proportional to size sampling with replacement), and stratification. We paired sampling plans with suitable estimators (simple, ratio, and probability proportional to size). We used area of the sampling unit as the auxiliary variable for the ratio and probability proportional to size estimators. All estimators were nearly unbiased, but precision was generally low (overall $\bar{x}$ coefficient of variation $[\mathrm{CV}]=29$ ). Coverage of $95 \%$ confidence intervals was only $89 \%$ because of the highly skewed distribution of the pronghorn counts and small sample sizes, especially with stratification. Stratification combined with accurate estimates of optimal stratum sample sizes increased precision, reducing the mean CV from 33 without stratification to 25 with stratification; costs increased $23 \%$. Precise results $(\bar{x}$ $\mathrm{CV}=13$ ) but poor confidence interval coverage $(83 \%)$ were obtained with simple and ratio estimators when the allocation scheme included all sampling units in the stratum containing most pronghorn. Although areas of the sampling units varied, ratio estimators and probability proportional to size sampling did not increase precision, possibly because of the clumped distribution of pronghorn. Managers should be cautious in using sampling plans and estimators to estimate abundance of aggregated populations.
\end{abstract}

J. WILDL. MANAGE. 59(1):129-137

Key words: aerial survey, Antilocapra americana, North Dakota, population estimation, pronghorn, strip transect.

Aerial surveys are widely used to estimate abundance for various animals, including wetland (Conroy et al. 1988), oceanic (Finley et al. 1987), and terrestrial (Bear et al. 1989) species. A variety of sampling plans and estimators have been used in surveys (see Seber 1982, 1986, 1992). Statistical sampling theory may suggest which of various sampling plans or estimators are appropriate under certain circumstances, but there may be restrictions such as using large sample sizes. Rules of thumb given for sample sizes (Moore and McCabe 1993:510) may not be appropriate for the skewed distributions often characteristic of wild animal populations. Known populations can be used in evaluating sampling plans and estimators.

Despite their importance and wide use, sampling plans and estimators have rarely been test-

\footnotetext{
${ }^{1}$ Present address: 6059 Jamestown College, Department of Mathematics, Jamestown, ND 58405, USA.
}

ed on wild animal populations for which actual abundance and distribution of individuals were known (Davis and Winstead 1980:244, Seber 1982:561); exceptions include a survey of bison (Bos bison) on an island (Wolfe and Kimball 1989) and a mule deer (Odocoileus hemionus) count within enclosed pastures (White et al. 1989). Most evaluations involved natural populations of unknown abundance and distribution (Bergerud and Manuel 1969, Redmond et al. 1981, Firchow et al. 1990) or simulated populations of known abundance and distribution (Zarnoch 1976, Caughley 1977). Even less is known about the performance of sampling plans and estimators when sampling animals tend to cluster. We obtained aerial counts and locations of pronghorn for 2 areas $\left(1,242\right.$ and $\left.2,387 \mathrm{~km}^{2}\right)$ in North Dakota in 1979, 1986, and 1987. Our objective was to evaluate several sampling plans and estimators on populations of known sizes of a species that is spatially clustered.

We thank M. D. Schwartz and R. M. Woodle for technical assistance, and E. Forgaard, J. W. 
Table 1. Size of study areas, number of sampling units $(M)$, total count $(M$ of pronghorn, and variance of $N$ for study areas with and without stratification in Bowman (1979 and 1987) and Slope counties (1986), North Dakota.

\begin{tabular}{|c|c|c|c|c|c|c|c|}
\hline \multirow[b]{2}{*}{ Study area } & \multirow{2}{*}{$\begin{array}{c}\text { Area } \\
\left(\mathbf{k m}^{2}\right)\end{array}$} & \multirow[b]{2}{*}{$M$} & \multirow{2}{*}{$\begin{array}{c}\text { Transect } \\
\text { lengths }(\mathrm{km})\end{array}$} & \multicolumn{2}{|c|}{ First survey ${ }^{\mathrm{a}}$} & \multicolumn{2}{|c|}{ Second survey ${ }^{b}$} \\
\hline & & & & $N$ & Variance $^{c}$ & $N$ & Variance \\
\hline \multicolumn{8}{|l|}{ Bowman } \\
\hline Total & 1,242 & 48 & $2.4-41.6$ & 201 & 51.4 & 630 & 373.5 \\
\hline Grassland stratum & 486 & 30 & $7.2-27.3$ & 185 & 61.4 & 355 & 311.1 \\
\hline Mixed stratum & 756 & 48 & 2.4-36.9 & 16 & 2.0 & 275 & 95.8 \\
\hline \multicolumn{8}{|l|}{ Slope } \\
\hline Total & 2,387 & 62 & $1.6-64.0$ & 350 & 62.5 & & \\
\hline Grassland stratum & 1,690 & 48 & $18.0-48.9$ & 343 & 69.5 & & \\
\hline Mixed stratum & 697 & 76 & $1.3-28.9$ & 7 & 0.1 & & \\
\hline
\end{tabular}

a Jul 1979 for Bowman area, Jul 1986 for Slope area.

b Jul 1987 for Bowman area only.

c Population variance, $\sigma^{2}=\Sigma_{i-1}^{M}\left(n_{i}-\mu\right)^{2} / M$, where $n_{i}$ is the count on unit $i, \mu$ is the population mean, and $M$ is the total no. of transects.

Wyckoff, and the University of North Dakota, Department of Geography, for habitat maps. We are grateful to J. E. Austin, R. R. Koford, W. E. Newton, J. R. Sauer, D. J. Twedt, and 4 anonymous referees for comments on earlier manuscript drafts. Aerial surveys were partially funded by North Dakota Pittman-Robertson Project W-67-R.

\section{STUDY AREAS}

We counted pronghorn in 2 areas in southwestern North Dakota. One area, in Bowman County, was $1,242 \mathrm{~km}^{2}$, including about $35 \%$ extensive grassland, $55 \%$ cultivated land interspersed with grassland, and $10 \%$ badland (steep and rugged terrain). The second area, in Slope County, was $2,387 \mathrm{~km}^{2}$, including about $65 \%$ extensive grassland, $25 \%$ mixed cultivation, and $10 \%$ badland.

\section{METHODS}

North Dakota Game and Fish Department personnel counted pronghorn in the 2 study areas by flying east-west linear strip transects that extended the length of the study area and were $0.8 \mathrm{~km}$ apart. Transects were searched $0.4 \mathrm{~km}$ on each side of the aircraft. Observers and pilots were experienced in surveys of pronghorn. Transects were 2.4-41.6 km long in the Bowman area and 1.6-64.0 km long in the Slope area. A Piper Super Cub was flown 96-128 km/hour at an altitude of $100-115 \mathrm{~m}$. When the pilot or an observer sighted pronghorn, the aircraft circled the herd so that all pronghorn in the herd could be counted. Where pronghorn detectability might be lower due to heterogeneous habitat, areas were searched thoroughly at an altitude of $25 \mathrm{~m}$. We recorded the number of pronghorn counted in each quarter section $\left(0.65 \mathrm{~km}^{2}\right)$ on field maps.

We used 2 surveys of the Bowman area, 1 in July 1979 and the other in July 1987, in which 201 and 630 pronghorn were seen, respectively, and a single July 1986 survey of the Slope area, in which 350 pronghorn were seen. We believe that counts were virtually exact, because of open terrain, narrow transect width, high visibility of pronghorn, and careful searching methods (Pojar et al. 1995). Nonetheless, because we could not determine visibility bias for the surveys, our results are conditional on observed distribution of pronghorn.

\section{Sampling Plans}

A sampling plan involves defining and selecting the sampling unit, choosing a sample size, and deciding on stratification. In addition, a population estimator must be selected. We selected combinations of sampling plans and estimators on the basis of previous use, suggestions by other researchers, or potential for producing valid estimates.

The sampling unit was a $0.8-\mathrm{km}$-wide linear transect variable in length (Table 1) according to size and shape of the study area or stratum. We examined 3 methods for selecting sampling units: (1) simple random sampling without replacement (SRS)(Cochran 1977:18), (2) probability proportional to size with replacement (PPS), and (3) systematic sampling (SYS). Under SRS, each sampling unit had an equal chance of being selected. With PPS sampling, the probability of choosing a sampling unit was proportional to the area of the sampling unit. With SYS, units were numbered 1 to $M$, where the total number of sampling units was $M=m p$, 
$m$ was the sample size selected from $M$ units, and $p$ was the number of possible systematic samples. The first unit was randomly chosen from among the first $p$ units, and then every $p$ unit following was selected.

We considered 3 levels of sampling intensity: 16,33 , and $50 \%$ of the total number of sampling units. Except in the stratified Slope area, the percentage of the area sampled was within $2 \%$ of sampling intensity.

We considered stratification and no stratification of study areas. On the basis of 1974 LANDSAT data, we stratified each study area into 2 vegetational types, grassland stratum and mixed stratum, thought to correspond to areas of high and low use, respectively, by pronghorn. Grassland stratum contained extensive grassland; the mixed stratum was composed of cultivated lands, badlands, and a small amount (10$14 \%$ ) of grassland. We used the same stratification for both years in the Bowman area. The grassland stratum was smaller than the mixed in the Bowman area, but the reverse was true for the Slope area (Table 1).

\section{Estimators of Abundance}

Depending on the selection method, we evaluated 1-4 estimators of abundance: simple (Cochran 1977:22-26, 207, 224), probability proportional to size (pps; note use of lower case to distinguish the estimator from PPS sampling) (Cochran 1977:253-254), separate ratio, and combined ratio estimators (Cochran 1977:150 162). We used the area of the sampling unit as the auxiliary variable for the pps and ratio estimators. When the surveyed area was stratified, an abundance estimate $\left(\hat{N}_{f}\right)$ and its variance were calculated independently in each stratum. Estimated overall abundance $(\hat{N})$ and its variance were obtained by summing estimates across strata.

Once a sample size, $m$, had been selected, the number of sampling units chosen from each stratum could be determined in many ways. Stratum sample sizes, $m_{f}$, may be allocated in a way that yields the minimum variance of the estimate, but this optimal allocation depended on the selection method and estimator used and on unknown population parameters (Cochran 1977:172). Optimal allocation with SRS using the simple estimator required that population variance of the count in each stratum be known (Cochran 1977:97-98). We tested an approximation of an optimal allocation:

$$
m_{j}=m \frac{\boldsymbol{M}_{j} \hat{p}_{j}}{\sum_{k=1}^{u} M_{k} \hat{p}_{k}},
$$

where $\hat{p}_{j}$ was the estimated proportion of pronghorn in stratum $j$, and $M_{f}$ was the total number of sampling units in stratum $j$. This method was optimal if sampling was SRS with the simple estimator and $\hat{p}_{j}$ (or equivalently $\hat{N}_{j}$ ) was proportional to the population variance of the count in the $j$ th stratum. The method was similar to that used by Siniff and Skoog (1964) and places greater sampling intensity where abundance is thought to be greater. For our evaluations, we asked a biologist familiar with western North Dakota, but who had not seen the pronghorn data, to estimate the proportion of pronghorn in each stratum. We used the same allocation method for all combinations of sampling plans and estimators and were able to compare our calculated sample sizes with the true optimal sample sizes because we had a known distribution of counts.

\section{Evaluation of Sampling Plans and Estimators}

For each of the 3 known population distributions (Bowman area, 1979, 1987; Slope area, 1986), we drew 1,000 random samples of the specified size according to the specified selection method. For example, there were 48 transects in the Bowman area; for a simple random sample of $33 \%$ intensity, we randomly drew 16 transects with equal probability and without replacement. For systematic sampling, we drew all possible samples.

We compared combinations of sampling plans and estimators on the basis of 3 criteria: accuracy of the estimator, confidence interval coverage, and cost. Accuracy of the estimators, $\hat{N}$, was of primary importance for estimating abundance, $N$. A useful measurement of accuracy is the mean square error (MSE), which is the variance of the estimator plus the squared bias. For all simulations, the percent difference between MSE and variance was $<1 \%$, so MSE approximated variance. If variance was equal to MSE, then there was no bias and accuracy was the same as precision. We used the $\mathrm{CV}$

$$
\mathrm{CV}=\frac{\sqrt{\operatorname{Var}(\hat{N})}}{N}
$$

as a measure of precision, facilitating comparisons across study areas and years. The smaller 
Table 2. Coefficient of variation (\%) of estimators of abundance ( $M$ determined from sampling plans at 3 intensities for known distributions of pronghorn in Bowman (1979 and 1987) and Slope counties (1986), North Dakota.

\begin{tabular}{|c|c|c|c|c|c|c|c|c|c|c|c|c|c|c|c|c|c|c|}
\hline \multirow{3}{*}{$\begin{array}{l}\text { Selection } \\
\text { method }^{\mathrm{a}}\end{array}$} & \multirow[b]{3}{*}{ Estimator ${ }^{b}$} & \multirow{3}{*}{$\begin{array}{l}\text { Strati- } \\
\text { fied }\end{array}$} & \multicolumn{4}{|c|}{ Bowman 1979} & \multicolumn{4}{|c|}{ Bowman 1987} & \multicolumn{4}{|c|}{ Slope 1986} & \multicolumn{4}{|c|}{ Average } \\
\hline & & & \multicolumn{4}{|c|}{$\begin{array}{c}\text { Sampling } \\
\text { intensity (\%) }\end{array}$} & \multicolumn{4}{|c|}{$\begin{array}{c}\text { Sampling } \\
\text { intensity (\%) }\end{array}$} & \multicolumn{4}{|c|}{$\begin{array}{c}\text { Sampling } \\
\text { intensity (\%) }\end{array}$} & \multicolumn{4}{|c|}{$\begin{array}{c}\text { Sampling } \\
\text { intensity (\%) }\end{array}$} \\
\hline & & & 16 & 33 & 50 & $\overline{\bar{x}}$ & 16 & 33 & 50 & $\overline{\bar{x}}$ & 16 & 33 & 50 & $\overline{\bar{x}}$ & 16 & 33 & 50 & $\bar{x}$ \\
\hline \multirow[t]{5}{*}{ SRS $^{c}$} & Simple & no & 56 & 35 & 25 & 39 & 48 & 30 & 21 & 33 & 41 & 26 & 18 & 28 & 48 & 30 & 21 & 33 \\
\hline & & yes & 38 & 20 & 11 & 23 & 48 & 29 & 20 & 32 & 22 & 10 & 2 & 11 & 36 & 20 & 11 & 22 \\
\hline & Ratio & no & 52 & 33 & 23 & 36 & 46 & 30 & 21 & 32 & 38 & 25 & 17 & 27 & 46 & 29 & 20 & 32 \\
\hline & Separate ratio & yes & 39 & 20 & 11 & 23 & 51 & 30 & 21 & 34 & 24 & 10 & 2 & 12 & 38 & 20 & 11 & 23 \\
\hline & Combined ratio & yes & 41 & 22 & 13 & 25 & 49 & 30 & 21 & 33 & 26 & 14 & 5 & 15 & 39 & 22 & 13 & 25 \\
\hline \multirow[t]{2}{*}{$\mathrm{PPS}^{\mathrm{d}}$} & $\mathrm{pps}^{\mathrm{e}}$ & no & 52 & 37 & 30 & 40 & 45 & 32 & 26 & 34 & 39 & 28 & 22 & 30 & 45 & 32 & 26 & 35 \\
\hline & & yes & 41 & 28 & 23 & 31 & 50 & 33 & 26 & 36 & 29 & 20 & 17 & 22 & 40 & 27 & 22 & 30 \\
\hline \multirow[t]{2}{*}{ SYS $^{f}$} & Simple & no & 50 & 38 & 13 & 34 & 39 & 27 & 19 & 28 & 44 & 32 & 13 & 30 & 44 & 32 & 15 & 31 \\
\hline & & yes & 50 & 16 & 9 & 25 & 54 & 29 & 29 & 37 & 32 & 12 & 2 & 15 & 45 & 19 & 13 & 26 \\
\hline
\end{tabular}

a The method used to select the sampling units.

b The estimator for the population count.

c Simple random sampling without replacement.

d Probability proportional to size with replacement sampling.

e Probability proportional to size estimator.

f Systematic sampling.

the $\mathrm{CV}$, the more precise the estimator. For the simple and pps estimators, we could calculate the exact $\mathrm{CV}$, but for the ratio estimators we used the estimated $\mathrm{CV}$

$$
\widehat{C V}=\frac{\sqrt{\frac{1}{\mathrm{r}} \sum_{i=1}^{r} \widehat{\operatorname{Var}}\left(\hat{N}_{i}\right)}}{N},
$$

where $\mathrm{r}$ was the number of repetitions of the simulation, and $\operatorname{Var}\left(\hat{N}_{i}\right)$ was the estimated variance of the population estimate for the $i$ th simulation.

The coverage of usual $95 \%$ confidence intervals was an important criterion to consider. For each simulation, we constructed nominal $95 \%$ confidence intervals:

$$
\hat{N}_{i}+t \sqrt{\hat{\mathbf{V}}\left(\hat{N}_{i}\right)}
$$

where $t$ was the 0.975 percentile of Student's $t$ distribution with $m-1 \mathrm{df}$ with no stratification and $m_{1}+m_{2}-2 \mathrm{df}$ with stratification. For each combination of sampling plan and estimator, we calculated the confidence interval coverage as the percentage of confidence intervals containing $N$.

For simplicity, we calculated cost for each simulated survey as the sum of the lengths of the transects and the travel distances between transects. These costs were averaged across simulations under a particular sampling plan to get the cost for that plan.

The large number of simulations we used ensured repeatability of results. To measure the performance of simulations, we calculated the $\mathrm{CV}$ of estimates of $\mathrm{CV}$, coverage, and cost for a number of sampling plans and estimators. We did not perform significance tests because all comparisons would have been significant $(\mathrm{P}<$ 0.001 ) due to the large number of simulations.

\section{RESULTS}

Repeatability of simulations was excellent (most CV $<1 \%$, with a few $\leq 3 \%$ ). Pronghorn counts ranged from 0 to $28(\bar{x}=4.2$, median $=$ 0 ) for Bowman 1979, 0-72 ( $\bar{x}=13.1$, median $=$ 3) for Bowman 1987, and 0-32 ( $\bar{x}=5.6$, median $=1)$ for Slope 1986. For grassland strata, pronghorn counts ranged from 0 to 28 ( $\bar{x}=6.2$, median $=1)$ for Bowman 1979, 0-40 ( $\bar{x}=11.3$, median $=0)$ for Bowman 1987, and 0-32 $(\bar{x}=7.2$, median $=4$ ) for Slope 1986. For mixed strata, pronghorn counts ranged from 0 to $7(\bar{x}=0.3$, median $=0)$ for Bowman 1979, 0-60 ( $\bar{x}=5.8$, median $=2.5)$ for Bowman 1987, and 0-3 $(\bar{x}=$ 0.1 , median $=0$ ) for Slope 1986 .

\section{Selection Method}

Without stratification, SRS was less precise (Table 2) than SYS sampling ( $\bar{x} \mathrm{CV}=33$ and 31 , respectively), but the results were opposite with stratification $(\bar{x} \mathrm{CV}=23$ and 26 , respectively). Probability proportional to size sampling was the least precise $(\bar{x} \mathrm{CV}=35$ without stratification, 30 with stratification). Correlation coefficients between sampling unit area and pronghorn count on the unit were $0.003-0.46$, 
explaining why PPS did not result in substantially more precise estimates.

Confidence interval coverage (Table 3 ) of PPS without stratification was higher $(\bar{x}=92 \%)$ than SRS $(\bar{x}=91 \%)$ but lower than SYS $(\bar{x}=94 \%)$. With stratification, PPS sampling gave higher coverage $(\bar{x}=92 \%)$ than SRS and SYS $(\bar{x}=86$ and $78 \%$, respectively). Coverages under systematic sampling were erratic (Table 3); for example, in the Slope area, the confidence interval coverage ranged between 50 and $100 \%$, depending on sampling intensity.

The average distance flown with PPS sampling without stratification was $461 \mathrm{~km}-9 \%$ lower than the average for SRS and SYS (509 and $507 \mathrm{~km}$, respectively). With stratification, the average distance flown with PPS sampling $(574 \mathrm{~km})$ was $21 \%$ lower than with SRS (728 $\mathrm{km})$ and $20 \%$ lower than with SYS (715 km).

\section{Sampling Intensities}

Precision and confidence interval coverage generally increased with increasing intensities and costs (Tables 2, 3, and 4) with some exceptions. The average confidence interval coverages at the 3 intensities $(16,33$, and $50 \%)$ without stratification were 87,94 , and $95 \%$, respectively, and with stratification were 87,91 , and $78 \%$, respectively.

Standard errors were generally underestimated at all intensities with the percent bias of the underestimated standard errors ranging from -45 to $-1 \%$. Only 6 standard error estimates had zero bias and a few under systematic sampling had a large positive bias. Without stratification and excluding systematic sampling, the percent bias of the standard errors consistently decreased as sample size increased with $-6 \%$ bias at $16 \%$ sampling intensity to $-0.9 \%$ bias at $50 \%$ sampling intensity. With stratification and excluding systematic sampling, percent bias increased from $-9 \%$ at $16 \%$ sampling intensity to $-11 \%$ at $50 \%$ sampling intensity.

\section{Stratification}

Stratification generally increased precision (Table 2) but reduced average confidence interval coverage (Table 3 ) and usually increased costs (Table 4). Except in the Bowman area in 1987, the method we used to allocate sample sizes yielded results close to actual optimal sample sizes; therefore, for a given combination of sampling plan and estimator, the greatest possible precision was nearly achieved.

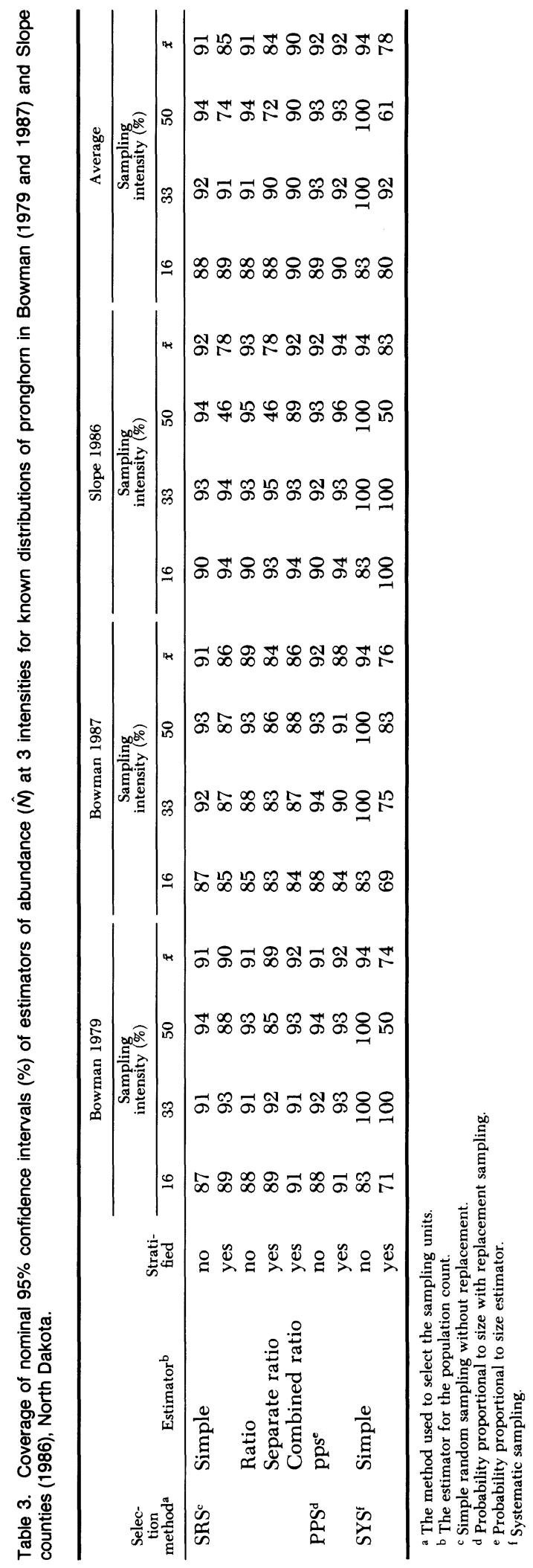


The overall average confidence interval coverage was $86 \%$ with stratification and $92 \%$ without stratification (Table 3 ), but this difference was not consistent at all intensity levels. At 16 and $33 \%$ intensity, average coverages were similar (87 and $91 \%$ with stratification and 87 and $94 \%$ without stratification). At $50 \%$ intensity without stratification, estimates were normally distributed and the average coverage was the nominal $95 \%$, but with stratification the coverage was only $78 \%$.

The gain in precision due to stratification for the Bowman area in 1979 came without a substantial increase in cost $(\bar{x}=3 \%)$. In the Slope area, there was an increase in cost $(\bar{x}=17 \%)$ due to stratification.

\section{Estimators}

We compared simple and ratio estimators for sampling plans in which SRS was used to sample transects, both stratified and not stratified. When the study area was not stratified, the simple estimator (Table 2) and the ratio estimator were similarly precise $(\bar{x} \mathrm{CV}=33$ and 32 , respectively). With stratification, the simple estimator was slightly more precise $(\bar{x} \mathrm{CV}=22)$ than the separate ratio $(\bar{x} \mathrm{CV}=23)$ or combined ratio estimators $(\bar{x} \mathrm{CV}=25)$.

The percentage of confidence intervals containing the actual pronghorn count (Table 3 ) was the same $(\bar{x}=91 \%)$ for the ratio and simple estimators without stratification. The combined ratio estimator gave better coverage $(\bar{x}=90 \%)$ than either the separate ratio $(\bar{x}=84 \%)$ or simple estimator $(\bar{x}=85 \%)$.

\section{DISCUSSION}

\section{Selection Method}

Although SRS and SYS were, on average, more precise than PPS, differences were not large. Confidence interval coverage and cost were consistently better for PPS sampling, especially with stratification. Caughley (1979:10) stated that selecting sampling units without replacement (e.g., SRS and SYS) gives more precise results than sampling with replacement (e.g., PPS) at the same intensity, but when intensity is $<10 \%$ there is little difference between the methods.

We found estimates to be precise under systematic sampling but confidence interval coverage was never nominal (Cochran 1977:205). Inadequate confidence interval coverage may have resulted from poor estimates of variance. Estimation of the variance of $\hat{N}$ can be a prob- lem in systematic sampling. There is no unbiased variance estimate unless additional assumptions are met (Zinger 1980, Wolter 1984). We encountered both over- and underestimated standard errors (Cochran 1977:213-226) with biases ranging from -45 to $87 \%$ of the true standard error. The limited number of samples obtained under systematic sampling (2-72 in our study) also may account for variability in coverage probabilities. For example, with $50 \%$ sampling intensity, we sampled either every even- or every odd-numbered sampling unit, resulting in only 2 distinct samples. Therefore, there are only 3 possible coverage percentages0,50 , or 100 - so the nominal confidence interval coverage of $95 \%$ cannot be attained.

\section{Stratification}

Stratification increased precision in the 2 populations in which the allocation we used was close to the theoretical optimal allocation that yields minimum variance of the estimate. Stratification in the Bowman area in 1987 did not, on average, improve precision. There may be 2 reasons for lack of improvement. First, the pronghorn population in the Bowman area increased from 1979 to 1987 , which may have induced animals to spread out from preferred habitat (grassland) into less preferred habitat (cultivated areas and badlands). Second, the habitat changed between surveys (Samuelson, unpubl. data); therefore, the 1974 LANDSAT information on vegetation we used to stratify the area was no longer current in 1987. These 2 changes resulted in strata having approximately the same number (Table 1) and distribution of pronghorn; consequently, our assumptions about the proportion of pronghorn in each stratum, and concomitantly our allocations, were no longer optimal.

Stratification generally increases precision (Siniff and Skoog 1964, Steel and Torrie 1980: 560-563), but precision can decrease with stratification if sample size allocation is far from optimal (Cochran 1977:99). The sample sizes we determined were close to optimal except for the sampling plans and estimators we evaluated using the Bowman area in 1987. In particular, the sample size results for SRS with the simple estimator indicate that, for these populations, in each stratum the population total is proportional to the population variance of the count. This relationship depends on the degree of aggregation (Taylor 1961) and may not hold for 
Table 4. Cost (distance in $\mathrm{km}$ ) of sampling plans at 3 intensities for known distributions of pronghorn in Bowman (1979 and 1987) and Slope counties (1986), North Dakota.

\begin{tabular}{|c|c|c|c|c|c|c|c|c|c|c|c|c|c|}
\hline \multirow{3}{*}{$\begin{array}{c}\text { Selec- } \\
\text { tion } \\
\text { methoda }^{\text {a }}\end{array}$} & \multirow{3}{*}{$\begin{array}{c}\text { Strati- } \\
\text { fied }\end{array}$} & \multicolumn{4}{|c|}{ Bowman } & \multicolumn{4}{|c|}{ Slope } & \multicolumn{4}{|c|}{ Average } \\
\hline & & \multicolumn{4}{|c|}{$\begin{array}{c}\text { Sampling } \\
\text { intensity (\%) }\end{array}$} & \multicolumn{4}{|c|}{$\begin{array}{c}\text { Sampling } \\
\text { intensity (\%) }\end{array}$} & \multicolumn{4}{|c|}{$\begin{array}{c}\text { Sampling } \\
\text { intensity (\%) }\end{array}$} \\
\hline & & 16 & 33 & 50 & $\overline{\bar{x}}$ & 16 & 33 & 50 & $\overline{\bar{x}}$ & 16 & 33 & 50 & $\overline{\bar{x}}$ \\
\hline \multirow[t]{2}{*}{ SRS $^{\mathbf{b}}$} & no & 185 & 352 & 514 & 350 & 350 & 657 & 994 & 667 & 268 & 505 & 754 & 509 \\
\hline & yes & 195 & 403 & 587 & 395 & 560 & 1,115 & 1,505 & 1,060 & 378 & 759 & 1,046 & 728 \\
\hline \multirow[t]{2}{*}{$\mathrm{PPS}^{\mathrm{c}}$} & no & 198 & 342 & 454 & 331 & 337 & 603 & 832 & 591 & 268 & 473 & 643 & 461 \\
\hline & yes & 189 & 348 & 464 & 334 & 511 & 837 & 1,093 & 814 & 350 & 593 & 779 & 574 \\
\hline \multirow[t]{2}{*}{$S_{Y S}^{d}$} & no & 190 & 353 & 514 & 352 & 351 & 661 & 972 & 661 & 271 & 507 & 743 & 507 \\
\hline & yes & 192 & 453 & 568 & 404 & 539 & 966 & 1,572 & 1,026 & 366 & 710 & 1,070 & 715 \\
\hline
\end{tabular}

a The method used to select the sampling units.

b Simple random sampling without replacement.

c Probability proportional to size sampling.

d Systematic sampling.

pronghorn populations during other seasons or for other species. The allocation method we used is strictly appropriate if sampling is SRS with the simple estimator, but it gave good results for all combinations of sampling plans and estimators. This may not always be the case, however, and other allocation methods (e.g., Cochran 1977:172) may be needed depending on the selection method, estimator, and knowledge of the population.

At smaller sample sizes, there was little difference between confidence interval coverage with or without stratification (both had low coverages). With larger sample sizes, we expected better confidence interval coverage, and found the coverage was close to the nominal value of $95 \%$ without stratification but was much lower with stratification.

Benefits of stratification are known, but little is known about its pitfalls. Stratification reduces sample sizes within each stratum. If small sample sizes are taken from a skewed distribution, confidence intervals based on an assumption of normally distributed counts may not be appropriate (Cochran 1977:27). Small sample sizes in strata also may bias standard error estimates, so Jolly (1969) suggested replacing each stratum's standard deviation by a single standard deviation calculated from the entire sample. We did not follow Jolly's suggestion because the standard deviation estimate is poor if an optimal allocation, such as our allocation method, is used and allocation is not proportional (i.e., $m_{f}=$ $m\left(M_{j} / \Sigma M_{j}\right)$ (Cochran 1977:136).

Stratification increased costs in Slope County due to a large difference in transect areas. For simulations for the Bowman (with and without stratification) and Slope areas (without stratifi- cation) the percentage of units selected and the percentage of the area sampled were approximately the same because most transects had similar length. In the stratified Slope area, however, transects in the grassland stratum were longer than those in the mixed stratum (Table 1). Because the grassland stratum was sampled more, a greater percentage of the area was sampled than sampling intensity indicated.

\section{Estimators}

The estimators we evaluated are widely used, require no assumptions about population distribution, and are easy to calculate, but their precision in simulations was not compelling except when sampling intensity was high. Caughley (1977) found the pps and ratio estimators to be more precise than the simple estimator when transects had unequal lengths, but all 3 performed equally well when transects had equal areas. In simulations, transect areas were not equal, but ratio and simple estimators had similar precision and confidence interval coverage with or without stratification. The simple estimator's variance was easier to calculate, and ratio estimators and their variances may be biased (Cochran 1977:160-161). We did not compare the pps estimator directly with simple and ratio estimators because the selection methods are different; therefore, effects of estimators and the selection method cannot be separated. Instead, we considered the pps estimator in association with PPS sampling. Jolly (1969) recommended the pps estimator for aerial surveys because he thought it was more precise when sampling units are unequal in area and because the formulas are simpler than those for the ratio estimator. Probability proportional to size sam- 
pling and ratio estimators may be more precise when the sampling unit area and the count are highly correlated (Cochran 1977:258), which we would expect for randomly or uniformly distributed animals. Our results suggest that when distributions of animals are clumped, perhaps due to habitat heterogeneity or the animals' behavior, the correlation between transect area and the count on that transect may be weak.

We observed that, on average and with only 2 strata, the simple, separate ratio, and combined ratio estimators had similar precision and confidence interval coverage except at $50 \%$ intensity, for which the coverage for the simple and separate ratio was much less. This disparity largely resulted from using simple and separate ratio estimators when sampling stratified transects under SRS at 50\% intensity in the Slope area. The low percentages occurred because the grassland stratum was completely sampled and, therefore, contributed zero as the variance estimate from this stratum. The mixed stratum had few pronghorn, and many samples included zero values; thus, the variance and ratio estimates were zero, so the simple and separate ratio estimators gave a variance estimate equal to zero and a confidence interval that was a single point. The combined ratio estimator, however, combined the information from both strata to calculate the ratio estimate, and gave a positive standard error estimate.

In simulations, the ratio estimators had small bias, but the separate ratio estimator may have higher bias than the combined ratio estimator when the number of strata is large. The separate ratio has smaller variance if the population density differs markedly among strata (Cochran 1977:165-167).

Research has been conducted on estimators that take into account factors such as large numbers of zero counts in a population; these might be appropriate for the highly skewed populations typical of animals that aggregate (Aitchison 1955, Pennington 1983). These estimators are difficult to calculate, have not been widely used, and assume a specific population distribution. If assumptions are met for these estimators, then confidence interval coverage should improve, but it is not clear that they would be more precise than estimators that make no assumptions about population distribution. Thompson (1992) discussed adaptive cluster sampling, which may give more precise estimates. Little is known about the procedure's effect on confidence interval coverage. There is some indication that the simple variance estimator may have a large bias when used with systematic sampling (Kraft, unpubl. data).

\section{MANAGEMENT IMPLICATIONS}

On the basis of our evaluations, if the study area habitat is heterogeneous and reliable current information is available, managers should stratify the study area and use an approximate optimal allocation. However, managers should be alert to problems with confidence interval coverage. Simple random sampling without replacement with the simple estimator is preferable unless the correlation between area and count is $>50 \%$ the $\mathrm{CV}$ of the area divided by the CV of the count (Cochran 1977:158). Under these conditions, the ratio estimator has smaller variance. Cochran (1977:165) stated that the separate ratio estimator was essentially unbiased when sample sizes were large enough in each strata for the variance formula to be valid for each stratum and when the square root of the number of strata times the $\mathrm{CV}$ of the mean area did not exceed 0.3 . With any sample size, the pps estimator with PPS sampling is unbiased. With small sample sizes and greater sampling intensity, the combined ratio estimator may give precise estimates. Variables other than area, such as the amount of preferred habitat on each sampling unit or the number of animals present during a previous survey, should also be examined to see how they correlate with the count on the sampling unit. If animals tend to concentrate in 1 stratum, then complete counting in that stratum may give precise estimates but poor confidence interval coverage for some combinations of sampling plans and estimators.

Choosing a sampling plan and estimator often has been based on familiarity rather than theory. Although no single combination of sampling plan and estimator is best for all situations, an informed choice can be made. Once the relative importance of accuracy, confidence interval coverage, and cost is determined, then results of our study can be used to help managers decide which sampling plan and estimator is most appropriate. Nonetheless, managers should be cautious in using any sampling plan on aggregated populations.

\section{LITERATURE CITED}

AITCHISON, J. 1955. On the distribution of a positive random variable having a discrete probability 
mass at the origin. J. Am. Stat. Assoc. 50:901908.

Allen, S. H., AND J. M. Samuelson. 1987. Precision and bias of a summer aerial transect census of pronghorn antelope. Prairie Nat. 19:19-24.

Bear, G. D., G. C. White, L. H. Carpenter, R. B. GILL, AND D. J. ESSEX. 1989. Evaluation of aerial mark-resighting estimates of elk populations. J. Wildl. Manage. 53:908-915.

Bergerud, A. T., AND F. Manuel. 1969. Aerial census of moose in central Newfoundland. J. Wildl. Manage. 33:910-916.

Caughley, G. 1977. Sampling in aerial survey. J. Wildl. Manage. 41:605-615.

- 1979. Sampling techniques for aerial censuses. Pages 9-14 in Aerial surveys of fauna populations. Australian Gov. Publ. Serv., Canberra.

Cochran, W. G. 1977. Sampling techniques. Third ed. John Wiley and Sons, New York, N.Y. 428pp.

Conroy, M. J., J. R. Goldsberry, J. E. Hines, AND D. B. STOTTS. 1988. Evaluation of aerial transect surveys for wintering American black ducks. J. Wildl. Manage. 52:694-703.

Davis, D. E., AND R. L. Winstead. 1980. Estimating the numbers of wildlife populations. Pages 221-245 in S. D. Schemnitz, ed. Wildlife management techniques manual. Fourth ed. The Wildl. Soc., Washington, D.C. 686pp.

Finley, K. J., J. P. Hickie, AND R. A. DAvis. 1987. Status of the beluga, Delphinapterus leucas, in the Beaufort Sea. Can. Field-Nat. 101:271-278.

Firchow, K. M., M. R. VAughan, aND W. R. MYTtON. 1990. Comparison of aerial survey techniques for pronghorns. Wildl. Soc. Bull. 18: 18-23.

JOLLY, G. M. 1969. Sampling methods for aerial censuses of wildlife populations. Pages 46-49 in W. G. Swank, R. M. Watson, G. H. Freeman, and T. Jones, eds. Proc. workshop on the use of light aircraft in wildlife management in East Africa. E. Afr. Agric. For. J. 34(spec. issue).

Moore, D. S., AND G. P. MCCABE. 1993. Introduction to the practice of statistics. Second ed. W. H. Freeman, New York, N.Y. 854pp.

PENNINGTON, M. 1983. Efficient estimators of abundance for fish and plankton surveys. Biometrics 39:281-286.

Pojar, T. M., D. C. Bowden, AND R. B. GILl. 1995.
Aerial counting experiments to estimate pronghorn density and herd structure. J. Wildl. Manage. 59:117-128.

Redmond, R. L., T. K. BICAK, AND D. A. JENni. 1981. An evaluation of breeding season census techniques for long-billed curlews (Numenius americanus). Pages 197-201 in C. J. Ralph and J. M. Scott, eds. Estimating numbers of terrestrial birds. Cooper Ornithol. Soc., Stud. Avian Biol. 6 .

SEBER, G. A. F. 1982. The estimation of population abundance. Second ed. Macmillan Publ., New York, N.Y. 654pp.

. 1986. A review of estimating animal abundance. Biometrics 42:267-292.

. 1992. A review of estimating animal abundance II. Int. Stat. Rev. 60:129-166.

SinIFF, D. B., AND R. O. SKoOg. 1964. Aerial censusing of caribou using stratified random sampling. J. Wildl. Manage. 28:391-401.

SteEL, R. G. D., AND J. H. Torrie. 1980. Principles and procedures of statistics. Second ed. McGrawHill, New York, N.Y. 633pp.

TAYLOR, L. R. 1961. Aggregation, variance and the mean. Nature 189:732-735.

Thompson, S. K. 1992. Sampling. John Wiley and Sons, New York, N.Y. 343pp.

White, G. C., R. M. BartmanN, L. H. Carpenter, AND R. A. GarRotT. 1989. Evaluation of aerial line transects for estimating mule deer densities. J. Wildl. Manage. 53:625-635.

Wolfe, M. L., AND J. F. Kimball. 1989. Comparison of bison population estimates with a total count. J. Wildl. Manage. 53:593-596.

WOLter, K. M. 1984. An investigation of some estimators of variance for systematic sampling. J. Am. Stat. Assoc. 79:781-790.

ZARNOCH, S. J. 1976. Evaluation of estimators of population size based on simulation techniques. Ph.D. Thesis, Virginia Polytech. Inst. and State Univ., Blacksburg. 191pp.

ZINGER, A. 1980. Variance estimation in partially systematic sampling. J. Am. Stat. Assoc. 75:206211.

Received 3 June 1993.

Accepted 2 September 1994.

Associate Editor: Conroy. 